\title{
Positive IgG Western Blot for Borrelia burgdorferi in Colombia
}

\author{
Ricardo Palacios/ ${ }^{+}$, Lyda E Osorio, Luis E Giraldo, Antonio J Torres, \\ Mario T Philipp*, Maria Teresa Ochoa
}

Centro Internacional de Entrenamiento e Investigaciones Médicas (CIDEIM), Cali, Colombia *Department of Parasitology, Tulane Regional Primate Research Center, Tulane University Medical Center, Covington, LA, USA

In order to evaluate the presence of specific IgG antibodies to Borrelia burgdorferi in patients with clinical manifestations associated with Lyme borreliosis in Cali, Colombia, 20 serum samples from patients with dermatologic signs, one cerebrospinal fluid (CSF) sample from a patient with chronic neurologic and arthritic manifestations, and twelve serum samples from individuals without clinical signs associated with Lyme borreliosis were analyzed by IgG Western blot. The results were interpreted following the recommendations of the Centers for Diseases Control and Prevention (CDC) for IgG Western blots. Four samples fulfilled the CDC criteria: two serum specimens from patients with morphea (localized scleroderma), the CSF from the patient with neurologic and arthritic manifestations, and one of the controls. Interpretation of positive serology for Lyme disease in non-endemic countries must be cautious. However these results suggest that the putative "Lyme-like" disease may correlate with positivity on Western blots, thus raising the possibility that a spirochete genospecies distinct from B. burgdorferi sensu stricto, or a Borrelia species other than B. burgdorferi sensu lato is the causative agent. Future work will focus on a survey of the local tick and rodent population for evidence of spirochete species that could be incriminated as the etiologic agent.

Key words: Borrelia burgdorferi - Colombia - morphea (localized scleroderma) - Lyme borreliosis - spirochete

Lyme borreliosis, the most frequently reported arthropod-borne disease in the United States of America (CDC 1997) is prevalent worldwide. In addition to the USA, it has been diagnosed in Europe and Asia, and there are unconfirmed reports of its identification in Australia, South America and South Africa (Dennis 1995). The spirochete Borrelia burgdorferi sensu lato, which is the etiologic agent of the disease, has only been isolated from patients, reservoir hosts or vector ticks in the Northern Hemisphere or, more precisely, from areas located north of the Tropic of Cancer (Dennis 1995). In the South, positive serologic tests, usually in the form of either the enzyme-linked immunosorbent assay (Elisa) or the indirect immunofluorescence assay (IFA), have been reported from Colombia (Muñoz et al. 1995), Bolivia (Ciceroni et al. 1994), Argentina (Stanchy \& Balague

\footnotetext{
This work was supported in part by grant RR00164 from the National Institutes of Health and Colciencias Young Investigator Program.

${ }^{+}$Corresponding author. Fax: +57-2-6672989. E-mail: cideim@cali.cetcol.net.co

Received 5 October 1998

Accepted 22 March 1999
}

1993), Peru (Need \& Escamilla 1991) and Africa (Schafrank et al. 1990, Marjolet et al. 1995) but the spirochete that putatively elicited these antibody responses has not been isolated. Moreover, only cases from Brazil included a Western blot (Yoshinari et al. 1997) that would comply with the criteria for positivity recently recommended by Dressler et al. (1993) and supported by the Centers for Disease Control and Prevention (CDC). According to these criteria, an IgG blot performed with serum from a patient with possible Lyme disease should be considered positive if five of the following ten $B$. burgdorferi-antigen bands are present: 18, 23 (OspC), 28, 30, 39, 41, 45, 58, 66, and $93 \mathrm{kDa}$.

Serum samples from patients who were diagnosed in Cali, Colombia as having disease manifestations that could be associated with Lyme borreliosis were obtained to evaluate the $\mathrm{IgG}$ antibody response to B. burgdorferi by Western blot. Positivity was assessed according to the Dressler criteria.

\section{PATIENTS AND METHODS}

Between May, 1995 and April, 1996, 20 serum samples and one sample of cerebrospinal fluid (CSF) were collected from patients presenting the following signs and/or symptoms. Five patients had dermatologic signs associated with early localized 
Lyme disease, namely erythema migrans (three patients) and lymphocytoma benigna cutis (two patients). Fifteen patients had dermatologic conditions that some have attributed to chronic Lyme disease (Hovmark 1994) such as morphea (localized scleroderma) (nine patients), lichen sclerosus et atrophicus (three patients) and scleroderma (three patients). One patient whose CSF was collected had chronic neurologic (facial palsy, headache and smooth papilledema), musculoskeletal (arthralgia), and dermatologic manifestations (leukocytoclastic vasculitis). In addition, twelve serum samples were collected in the area of Tumaco, Colombia from individuals without clinical manifestations associated with Lyme borreliosis, namely cutaneous leishmaniasis (four patients), suspected cutaneous leishmaniasis (four patients) and mucosal leishmaniasis (one patient) and from three healthy donors who resided in Cali. All of the samples were analyzed by IgG Western blot using the QualiCode ${ }^{\mathrm{TM}}$ Lyme disease kit (Immunetics, Inc. Cambridge, MA), following the recommendations of the manufacturer. The antigen used in this kit is derived from a low passage B31 strain of B. burgdorferi. IgM Western Blot was not performed because all the patients had more than three months of illness.

\section{RESULTS}

Four samples fulfilled the Dressler criteria of positivity for an IgG Western blot. Two of the positive serum samples were from patients with morphea. The third sample was the CSF from the patient with neurologic and arthritic manifestations. In the absence of criteria of Western blot for CSF samples, the CSF Western blot was interpreted as positive following the criteria used for serum samples. These three samples contained antibody reacting with $\mathrm{P} 21$ (P18), P30, P41 and P45. The fifth band was P58 in the morphea cases and P28 in the other case (Fig. 1). Antibody to the P21 (P18) band was present only in these three samples. The three patients from the study group that presented with morphea live in the Department of Valle del Cauca (two) and in Antioquia (one). They had not visited other countries previously. The patient with neurologic and arthritic manifestations resides in Valle del Cauca and visited New York after the symptoms began. None of the patients referred to tick bites.

The fourth positive sample came from a patient with mucosal leishmaniasis but without manifestations of Lyme borreliosis (Fig. 2). Of the five bands detected, only two were shared with the other three samples (P41 and P45). Notably, antibodies to the P41 and P45 bands were present in most of the samples (32/33 and 26/33, respectively). Anti-

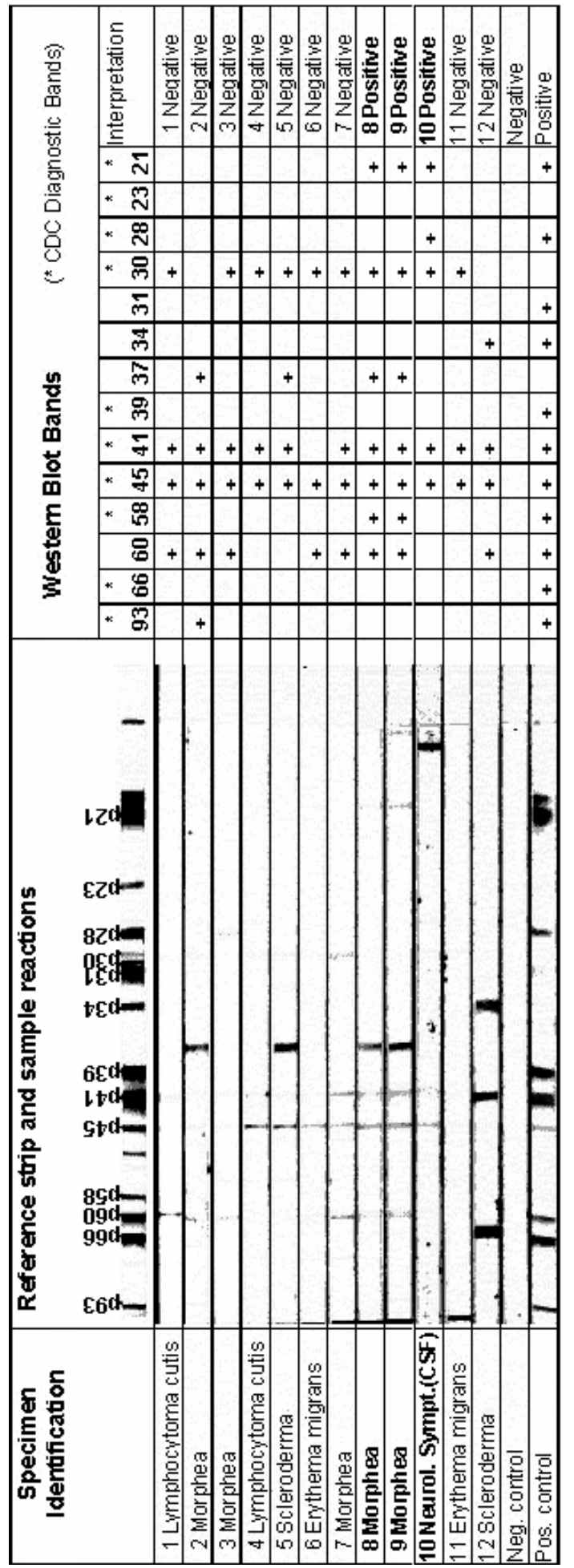

Fig. 1: IgG Western blot of serum (specimens 1-9, 11, 12) and cerebrospinal fluid samples (specimen 10) from patients with signs and symptoms associated with Lyme borreliosis. Blot was performed as described in the Methods section. 


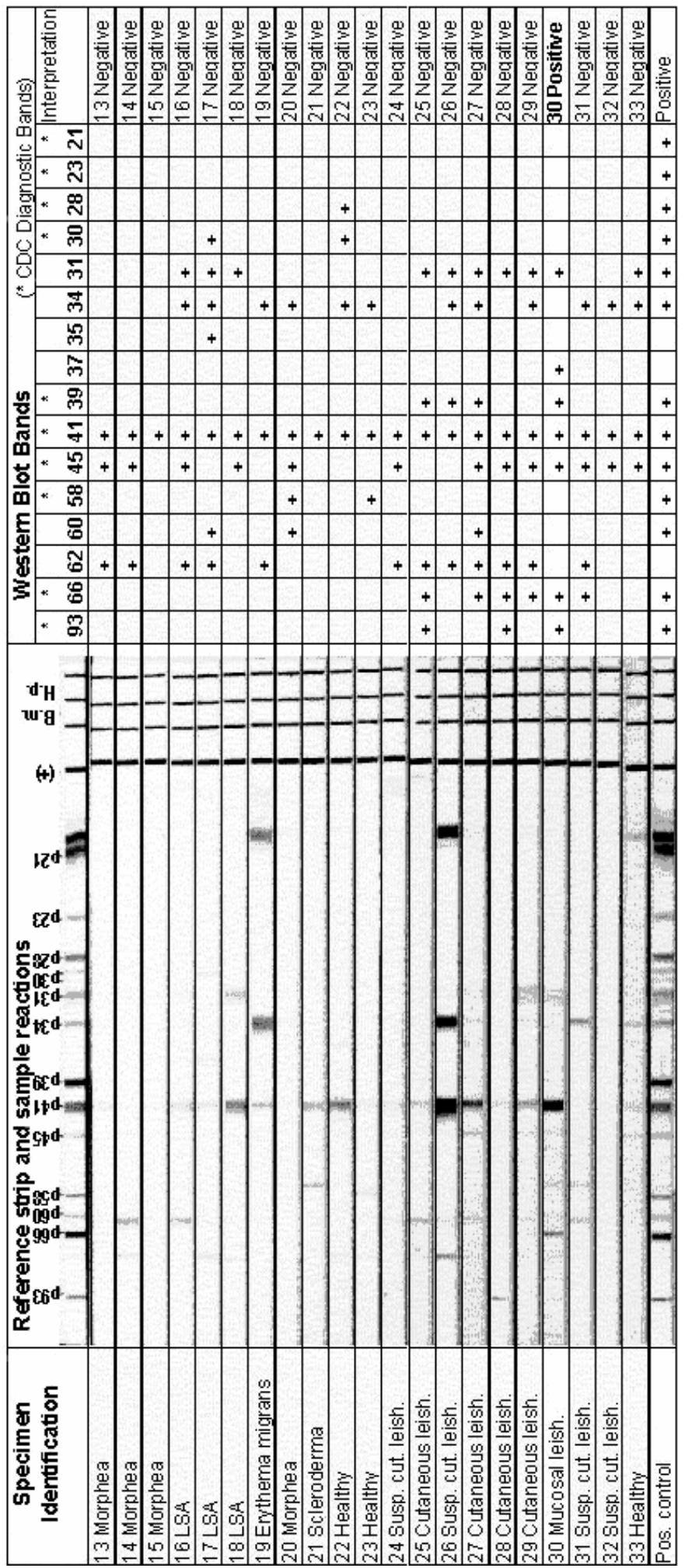

Fig. 2: IgG Western blot of serum samples from patients with signs and symptoms associated with Lyme borreliosis (specimens 1321 ) and from patients that were either healthy or presented with signs and symptoms of other endemic diseases of the area (specimens 22-33). Blot was performed as described in the Methods section. LSA: lichen sclerosus et atrophicus; susp. cut. leish.: suspected cutaneous leishmaniasis. 
body to P30 was found in eleven of the 21 patients with manifestations associated with Lyme borreliosis and in only one of the negative controls. One of the patients with morphea improved after antibiotic treatment with Doxycycline.

\section{DISCUSSION}

The interpretation of positive serologies in nonendemic countries must be cautious in the light of results obtained recently from the analysis of human serum samples from Papua New Guinea. These samples were analyzed for the presence of anti-B. burgdorferi $\mathrm{IgG}$ antibodies by a two-tiered system of analysis (Burkot et al. 1997), which includes a sensitive Elisa as the first tier, and a Western blot assessed by the Dressler criteria as the second tier (Johnson et al. 1996). A large proportion of serum samples $(57 \%)$ were positive by the Dressler criteria for IgG positivity despite the fact that in Papua New Guinea all known arthropod vectors of the Lyme disease spirochete are absent (Burkot et al. 1997). Our work is the third independent study reporting positive serologies for $B$. burgdorferi in patients with morphea in the northwest of South America (Arocha-Sandoval et al. 1994, Muñoz et al. 1995). In addition, we found another positive seum specimen from a more recent patient with morphea (data not shown). This specimen was tested using a different IgG Western blot kit (Marblot Strip TM MarDx Diagnostics Inc., Carlsbad, CA).

The association between morphea and Lyme borreliosis is not clear. Some studies that included attempts to either recover spirochetal DNA from host samples by the polymerase chain reaction or spirochetes by in vitro cultivation did not show this association (Fan et al. 1994, Dillon et al. 1995), whereas other studies provided supportive evidence for it (Aberer et al. 1991, Shempp et al. 1993, Trevisan et al. 1996). These contradictions might be explained by differences in the clinical signs and symptoms caused by each one of the $B$. burgdorferi sensu lato genospecies (Hovmark 1993, Schmidt 1997). Thus, morphea is not associated with $B$. burgdorferi sensu stricto infections, the predominant species in North America (CDC 1997).

On the other hand, our findings suggest serologic differences between our patients and those of confirmed Lyme-disease cases reported in North America and Europe as follows: (1) absence of detectable antibodies to P93 and P39. These antigens are known to be $B$. burgdorferi-specific (Magnarelli 1995); (2) nonspecificity of P45; antibodies to P45 were present in most samples, suggesting that other infections in the population may result in cross reactions, such as the positive West- ern blot observed in the individual with mucosal leishmaniasis (Fig. 2) which has a clearly different antigenic pattern to the other positive cases and absence of clinical manifestations associated with Lyme borreliosis; (3) P21 and to a lesser extent P30 seem to be specific for the studied population.

Hence, presentation with morphea could be an indicator of the presence of a different genospecies of $B$. burgdorferi sensu lato in Colombia or of a different Borrelia species. These results provide evidence that the putative Lyme-like disease may correlate with positivity of Western blots, thus raising the possibility that a spirochete genospecies distinct from $B$. burgdorferi sensu stricto can be the causative agent. Clearly, further studies are required in Colombia to confirm the etiology and association of morphea with a Borrelia species. that is distinguishable from B. burgdorferi sensu stricto. A survey of ticks and rodents in different areas of Valle del Cauca, is underway.

\section{ACKNOWLEDGEMENTS}

To dermatotologists from the Hospital Universitario del Valle for referring their patients; to the secretarial help of Christie Trew and to the photographic skills of Murphy Douwois.

\section{REFERENCES}

Aberer E, Klade H, Stanek G, Gebhart W 1991. Borrelia burgdorferi and different types of morphea. Dermatologica 182: 145-154.

Arocha-Sandoval F, Amesty-Valbuena A, Urbina M, Durango AI, Vargas-Montiel H 1994. Detección de anticuerpos para Borrelia burgdorferi en una población del Estado del Zulia. Invest Clin 35: 91104.

Burkot TR, Schriefer ME, Larsen SA 1997. Cross-reactivity to Borrelia burgdorferi proteins in serum samples from residents of a tropical country nonendemic for Lyme disease. J Infect Dis 175: 466469.

CDC - Centers for Diseases Control and Prevention 1997. Lyme disease - United States, 1996. Morb Mortal Wkly Rep 46: 531-535.

Ciceroni L, Bartoloni A, Guglielmetti P, Paradisi F, Barahona HG, Roselli M, Ciarrocchi S, Cacciapuoti B 1994. Prevalence of antibodies to Borrelia burgdorferi, Borrelia parkeri and Borrelia turicatae in human settlements of the Cordillera Province, Bolivia. J Trop Med Hyg 97: 13-17.

Dennis DT 1995. Lyme disease. Dermatoepidemiology 13: 537-551.

Dillon WI, Saed GM, Fivenson DP 1995. Borrelia burgdorferi DNA is undectectable by polymerase chain reaction in skin lesions of morphea, schleroderma, or lichen sclerosus et atrophicus of patients from North America. J Am Acad Dermatol 33: 617-620.

Dressler F, Whalen JA, Reinhardt BN, Steere AC 1993. Western blotting in the serodiagnosis of Lyme disease. J Infect Dis 167: 392-340. 
Fan W, Leonardi CL, Penneys NS 1994. Absence of Borrelia burgdorferi in patients with localized scleroderma (morphea). J Am Acad Dermatol 33: 682684.

Hovmark A 1993. Role of Borrelia burgdorferi in lymphocytomas and sclerotic skin lesions. Clin Dermatol 11: 363-7.

Johnson BJB, Robbins KE, Bailey RE, Cao BL, Sviat SL, Craven RB, Mayer LW, Dennis DT 1996. Serodiagnosis of Lyme disease: accuracy of a two-step approach using flagella-based ELISA and immunoblotting. J Infect Dis 174: 346-353.

Magnarelli LA 1995. Current status of laboratory diagnosis for Lyme disease. Am J Med 98: 10S-12S.

Marjolet M, Gueglio B, Traore M 1995. Does Lyme disease (or an analogous disease) exist in Mali, West Africa? Trans $R$ Soc Trop Med Hyg 89: 387.

Muñoz A, Orrego JJ, Salazar M, Jaramillo D, Montoya F, Uribe O, Jaramillo A 1995. Reactividad humoral contra Borrelia burgdorferi en pacientes con enfermedades dérmicas y reumáticas. Acta Med Colomb 20: 257-261.

Need JT, Escamilla J 1991. Lyme disease in South
America? J Infect Dis 163: 681-682.

Schafrank SN, Kurban AK, Martone G 1990. Lyme disease acquired in southeast Africa. Arch Dermatol 126: 685-686.

Schempp C, Bocklage H, Lange R, Kölmel HW, Orfanos CE, Gollnick H 1993. Further evidence for Borrelia burgdorferi infection in morphea and lichen sclerosus et atrophicus confirmed by DNA amplification. $J$ Invest Dermatol 100: 717-720.

Schmidt BL 1997. PCR in laboratory diagnosis of human Borrelia burgdorferi infections. Clin Microbiol Rev 10: 185-201.

Stanchy NO, Balague LJ 1993. Lyme disease antibodies against Borrelia burgdorferi in farm workers in Argentina. Rev Saú Públ 37: 305-307.

Trevisan G, Stinco G, Nobile C, Bonin S, Stanta G 1996. Detection of Borrelia burgdorferi in skin biopsies from patients with morphea by polymerase chain reaction. J Eur Acad Dermatol Venerol 6: 15-19.

Yoshinari NH, Leme PJ, Nazario VL, Ishikawa M, Barros DM, Pirana S, Henrique A, Schumaker TT 1997. Perfil da Borreliose de Lyme no Brasil. Rev Hosp Clin Fac Med São Paulo 52: 111-117. 
Positive Immunoblot for B. burgdorferi in Colombia - Ricardo Palacios et al. 